\title{
¡A la estrella más cercana en dos semanas!
}

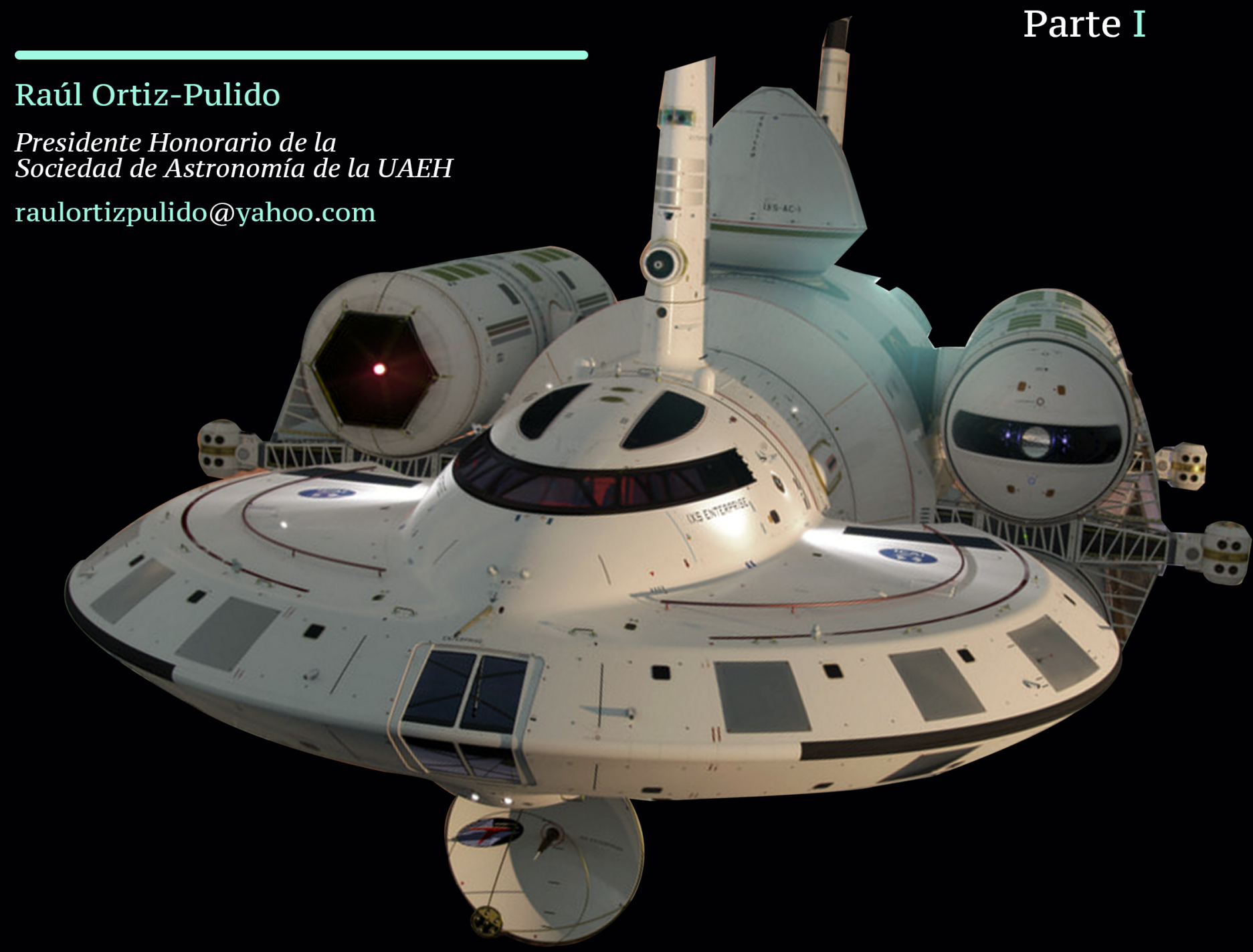

\section{RESUMEN}

¿Es posible viajar en el espacio a una velocidad mayor a la de la luz? Albert Einstein planteó que esto es imposible; sin embargo, dos científicos de la actualidad Miguel Alcubierre y Harold White, afirman lo contrario. ¿Alguna vez el ser humano logrará el sueño de visitar un planeta de alguna estrella lejana, gracias a esta posibilidad?

Palabras clave: Miguel Alcubierre, Harold White, velocidad de la luz.

\section{ABSTRACT}

Is it possible to travel through space faster than the speed of light? Albert Einstein said that it is not; however, two scientists of our time, Miguel Alcubierre and Harold White, claim the opposite. Would it be feasible for humans to visit a distant star and fulfill our dream?

Keywords: Miguel Alcubierre, Harold White, speed of light. 
¡No lo podía creer, podría conocer la nave que llevaría a la humanidad al espacio interestelar! Al menos así lo afirmaba la nota periodística publicada el 11 de junio de 2014. Dudando aún de la veracidad de la información, me animé a leerla, porque había sido publicada en un periódico de circulación nacional, un periódico serio.

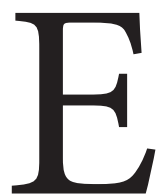

1 texto estaba compuesto en general, por imágenes que presentaban a la "IXS Enterprice", la pretendida nave interestelar información señalaba que la nave estaba aún en etapa de diseño por la NASA y que el concepto había sido desarrollado gracias al trabajo del doctor Harold White, jefe del laboratorio de Propulsión Avanzada Espacial de dicha agencia. Se informaba también que dicho desarrollo había sido posible gracias a un modelo matemático presentado por el físico mexicano Miguel Alcubierre en 1994. Allí se indicaba que la nave, "engañando a la física", podría viajar 10 veces más rápido que la luz.

Aún con dudas, compartí esta información con los miembros de la Sociedad de Astronomía de la Universidad Autónoma del Estado de Hidalgo, preguntándoles si ellos sabían algo más. En poco tiempo ya estábamos discutiendo la veracidad de la nota. Varios dijeron que era imposible, pues, de acuerdo con las ecuaciones de Einstein, no se puede viajar más rápido que la luz. Uno de los miembros más incrédulos, el Ingeniero Jorge Carrera, dijo:

- ¡Es una tomadura de pelo! La nota señala que la nave tendría un empuje Warp, una tecnología de ciencia ficción que fue presentada en la serie televisiva Viaje a las Estrellas. Y agregó: - Si todo fuera igual que en la serie, entonces los motores Warp se alimentarían con un elemento especial, el Inoptenio, ique no ha sido descubierto aún! -.

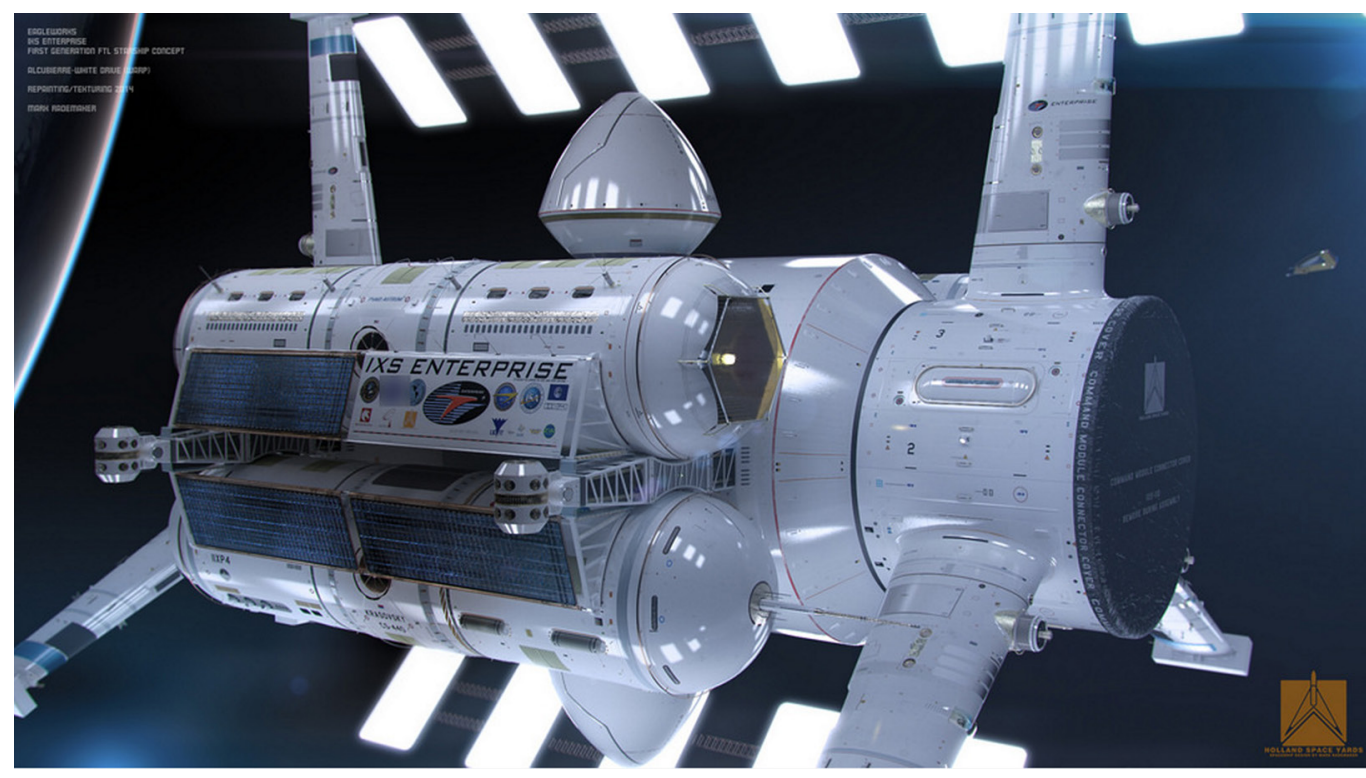

Representación artística de cómo quedaría el motor Warp montado en la nave IXS Enterprise. Créditos: Nasa

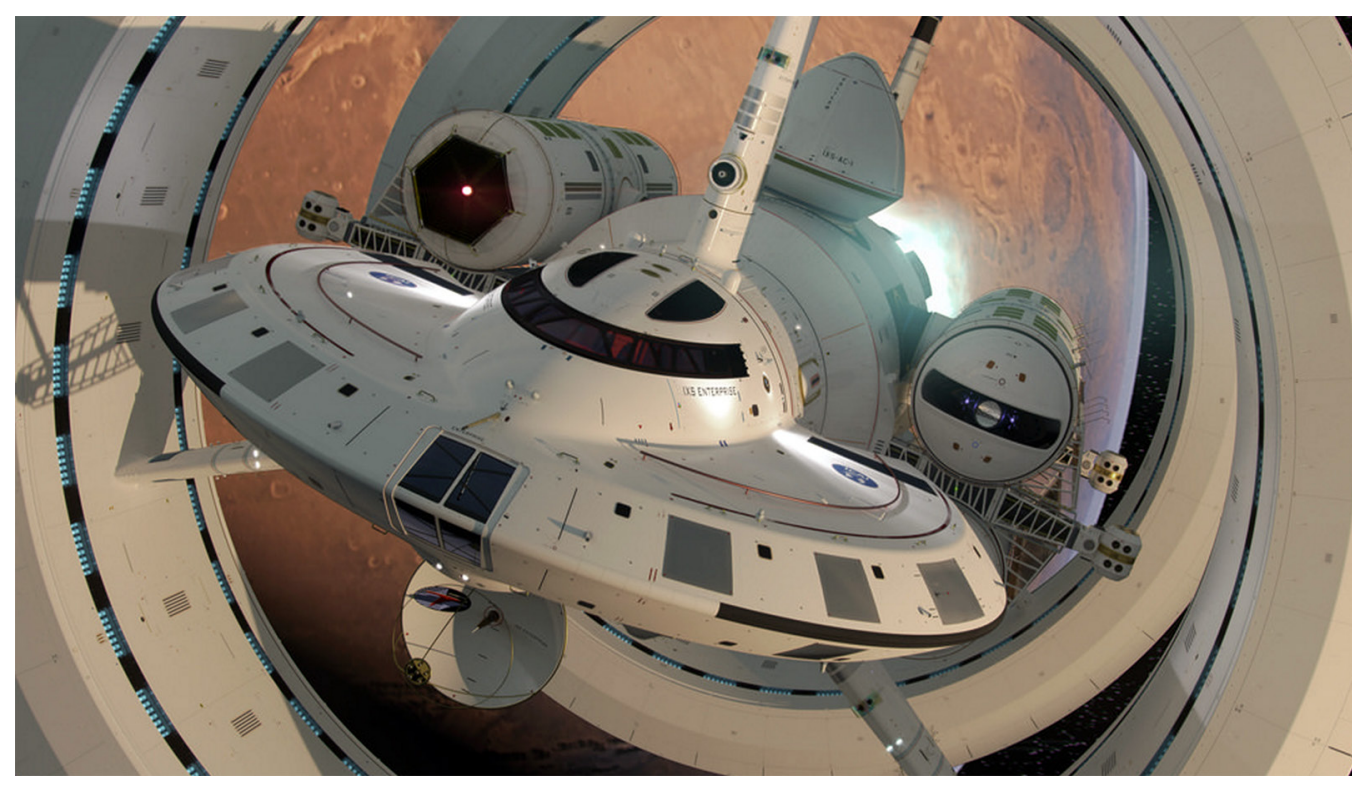

Imagen artística de lo que podría ser la nave IXS Enterprise.

Créditos: Nasa 


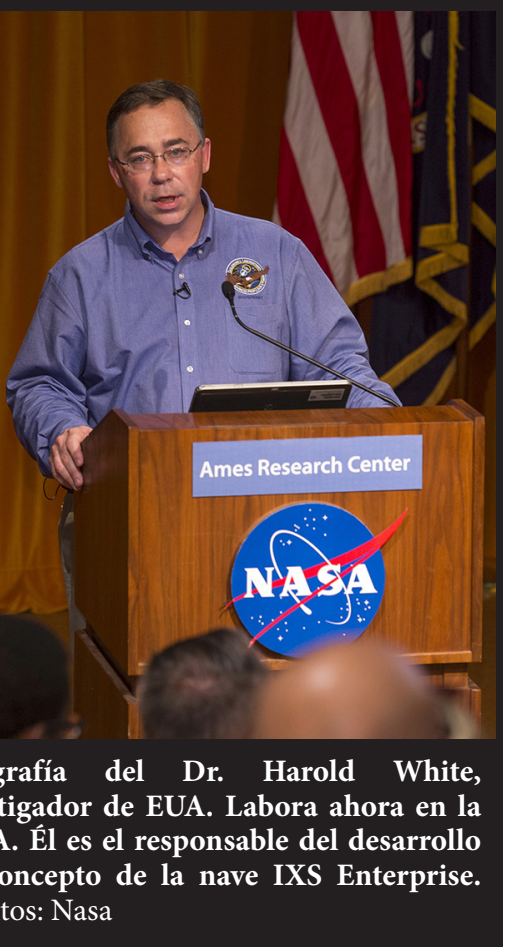

Esos dos aspectos, la imposibilidad señalada por la física de no poder viajar más rápido que la luz y el nombre extrañamente sospechoso de empuje Warp, me hicieron dudar aún más de la veracidad de la información. Al no ser yo un físico, y debido a ello no contar con la habilidad para entender y definir las ecuaciones implicadas, me pregunté cómo podría contribuir a esta discusión que yo mismo había iniciado.

Afortunadamente la nota señalaba nombres, los de los dos físicos y el de la nave. Con esas hebras de información me puse a investigar. El resultado me sorprendió un poco. Los dos científicos

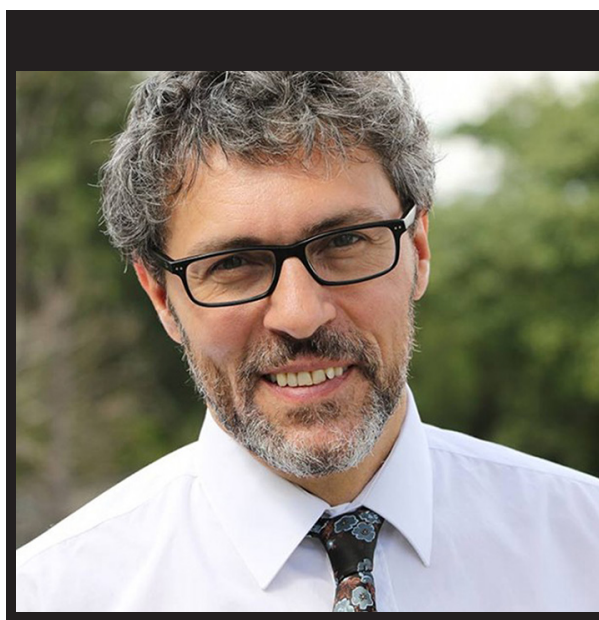

Dr. Miguel Alcubierre, investigador mexicano. Trabaja actualmente en la UNAM. Él desarrolló los modelos matemáticos en los que se basa la propulsión de la nave IXS Enterprise. Créditos: Nasa existen. El mexicano es el director actual del Instituto de Investigaciones Nucleares de la UNAM y el estadounidense efectivamente trabaja en la NASA. El mexicano creó la ecuación que se indica. La idea se le ocurrió mientras veía uno de los programas de Viaje a las Estrellas en 1990, al estar haciendo sus estudios de doctorado en Inglaterra con temas relacionados a las ecuaciones de Einstein. Después de crear la fórmula dijo que había sido más fácil de lo que imaginó. A él se le facilitan mucho las matemáticas y de pequeño pensó en ser astrónomo. Por su parte, Harold
White ha trabajado con tecnologías alternativas para impulsar cohetes. De hecho, ha recibido medallas de la NASA en reconocimiento a sus investigaciones aplicadas y ha organizado al menos una reunión de científicos para discutir seriamente las posibilidades de viajar más rápido que la luz.

Esta parte de mi investigación me indicó que los dos científicos existen y que ambos han trabajado en el tema de viajar más rápido que la luz. Me faltaba investigar sobre la nave. Eso, amable lector, le invito a investigarlo. $\mathrm{H}$

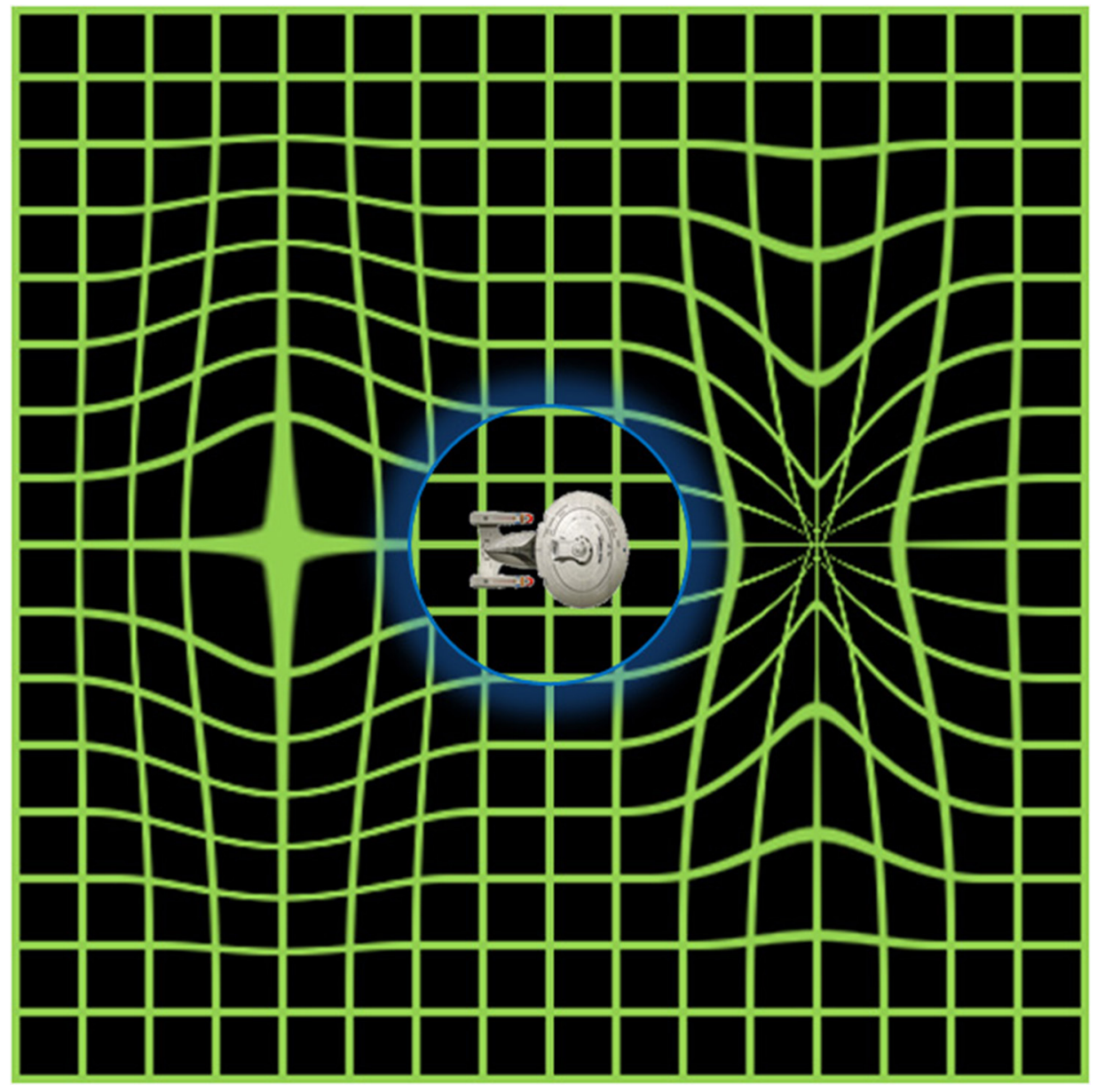

Representación gráfica de cómo podría ser el modo de propulsión de la nave IXS Enterprise. La nave contraerá el espacio-tiempo en la proa (parte delantera) y lo expandirá en la popa (parte trasera). Eso creará una onda sobre la que se montará la nave y gracias a ello avanzará como un surfista sobre una ola. Créditos: Nasa

\section{Referencias}

Para información del Dr. Miguel| Para conocer la nave: Alcubierre:

h t t p : / / ww w.excelsior.com. mx / nacional/2013/10/07/922176

Para información del Dr. Harold G. White: https://en.wikipedia.org/wiki/Harold_G_ White h t t p: // www.excelsior.com.mx/ global/2014/06/11/964633

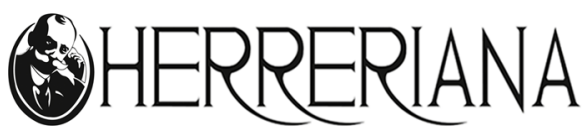

